\title{
Quantitative aspects of radon daughter exposure and lung cancer in underground miners
}

\author{
C EDLING AND O AXELSON \\ From the Department of Occupational Medicine, University Hospital, S-581 85 Linköping, Sweden
}

\begin{abstract}
Epidemiological studies have shown an excessive incidence of lung cancer in miners with exposure to radon daughters. The various risk estimates have ranged from six to 47 excess cases per $10^{6}$ person years and working level month, but the effect of smoking has not been fully evaluated. The present study, among a group of iron ore miners, is an attempt to obtain quantitative information about the risk of lung cancer due to radon and its daughters among smoking and non-smoking miners. The results show a considerable risk for miners to develop lung cancer; even non-smoking miners seem to be at a rather high risk. An additive effect of smoking and exposure to radon daughters is indicated and an estimate of about 30-40 excess cases per $10^{6}$ person years and working level month seems to apply on a life time basis to both smoking and non-smoking miners aged over 50.
\end{abstract}

Bronchogenic lung cancer is a well-established occupational disorder in uranium miners and in other miners with exposure to radioactive decay products of radon (radon daughters).' Recent studies of various mining groups seem to indicate that an increased risk of lung cancer mortality may persist even at the usually applied exposure standard of four working level months a year. ${ }^{2}$ This standard is a concentration-time product, and one working level month (WLM) is defined as an exposure for 170 hours to a concentration of one working level, which is any combination of short-lived daughters of 222 radon per litre of air that will result in the ultimate release of $1.3 \times 10^{5} \mathrm{MeV}$ of alpha energy during complete decay through radium $C^{\prime}$ (polonium 214).

The bronchial epithelium and particularly the basal stem cells are considered to be the tissue predominantly at risk from the inhalation of radon daughters. Theoretical calculations of the dose to the epithelium tend to be uncertain, however, because of the difficulties in estimating the deposition of particles to which the radon daughters are attached, as well as the efficacy of the clearance mechanisms and the thickness of the mucus layer. ${ }^{3}$

The cumulated information from studies in several countries indicates that a life-time exposure, taken as 30 years of underground work at the present standard of $4 \mathrm{WLM} /$ year, or $120 \mathrm{WLM}$ in total, might result in an excess of lung cancer greater than twofold. ${ }^{2}$ In view of a possible adverse effect also from low

Received 6 July 1982

Accepted 3 August 1982 levels of exposure, in several countries there is now a growing concern about the consequences of increasing radon concentrations in dwellings due to decreased ventilation for energy saving purposes; in Sweden a 2.5-fold increase in exposure levels might have taken place since the mid-1950s. Levels exceeding the acceptable limits for miners are not uncommon in homes, according to preliminary observations in country-wide measurements that are still being carried out. ${ }^{4} \mathrm{~A}$ few years ago, the Swedish Energy Commission indicated that the present levels of radon daughters in dwellings may contribute considerably to the lung cancer morbidity, ${ }^{5}$ and in the United States it has been estimated that a few thousand of the annual lung cancers may have been induced by radon levels that typically occur in homes. ${ }^{67}$ The available risk estimates, however, are obtained from miners and are uncertain as they are derived from rather small populations. The different conditions under which the environmental and occupational exposures take place also contribute to the difficulties involved in these comparative hazard evaluations. It may even be suggested that certain hygienic differences between various mines may act to modify the effects, and therefore one should not perhaps expect any particular precise concordance between the quantitative estimates of exposure to radon daughters and incidence of lung cancer as obtained from the mining populations in various countries throughout the world. It seems desirable, however, that as many exposed mining populations as possible are studied to provide information that will 182 
permit increasingly accurate hazard evaluations in the future.

The present study, among the Grängesberg miners in southern central Sweden, is an attempt to obtain quantitative information about the risk of lung cancer due to radon and its daughters from one more mining population, which is mature in age and has had a relatively moderate exposure. An overall evaluation of the high lung cancer mortality among these miners for $1957-80$ has been presented elsewhere, ${ }^{8}$ and a 16-fold increase in risk of this disorder was found compared with non-miners in the same geographical area.

\section{The mine}

Mining of iron ore in the Grängesberg area has been carried out since mediaeval times. By 1910 the open pit mining had reached its limits at depths of $70-100 \mathrm{~m}$ and mining operations started underground, nowadays mainly around $600 \mathrm{~m}$, the deepest parts reaching $800 \mathrm{~m}$. Before 1945 the ventilation was "natural" and the mine still rather shallow. Mechanical ventilation was introduced in 1955-6, however, and air was taken down through old shafts and transported for some distance underground to gain heat from the ground in wintertime. This new ventilation considerably improved the dust levels in the mine. In 1969 large diesel-driven equipment was introduced, and there was a demand for a considerable increase in the ventilation of the workplace. To meet this need, the present ventilation, present from 1970, was constructed as a forced system with two circular, vertical ventilation shafts with a capacity of 1350000 $\mathrm{m}^{3} /$ hour.

The atmosphere in a mine is complex and may contain a variety of more or less well recognised carcinogenic agents-for example, arsenic, asbestos, or asbestiform minerals, metals such as chromium and nickel, and diesel exhausts. In this mine, however, hygienic measurements have not shown any arsenicals or asbestiform minerals. Geochemical investigations have found that the ore contains only traces of nickel and chromium. Since large diesel driven equipment was introduced as late as 1969 , exposure to diesel exhaust is unlikely to have had any aetiological importance for the lung cancers of this mining population during the 1960s and 1970s. Exposure to radon and radon daughters, therefore, seems to remain as the most plausible cause of the excess of lung cancer.

\section{Material and methods}

SOURCE OF SUBJECTS

The register of deaths and burials in the parish of
Grängesberg, a mining community with about 3000 inhabitants, was used as the source of subjects for the study; only men over 50 were included. During 195780,57 individuals had died of lung cancer, 52 of whom could be traced as having been underground miners. During the first part of the study period there was an increasing frequency of new deaths from lung cancer a year from 1957 to 1966 (fig), followed by a levelling out at about eight cases for each three year period.

For the purpose of quantifying the life time risk of developing lung cancer due to radiation in this population, it seemed reasonable to take into account only the period of more stable incidence-that is, since 1966, when the full risk might have developed. For certain practical and economical reasons with regard to the selection of controls, the study period was terminated by the end of 1977. The cases considered in this evaluation are consequently those men who had died of lung cancer (ICD 162) in the parish during 1966-77 and as referents we have taken those who died of other causes during the same period (table 1).

A subset of the two series was also used for more detailed evaluation of the effects of smokingnamely, those who, according to the occupational title in the register, had been miners. Each of the miner cases in the subseries was matched with a dead referent who had not died from cancer, was also a miner, and, according to the register of deaths and burials, had the same year of birth ( \pm 6 years) and year of death ( \pm 2 years).

To measure the risk of lung cancer, the necessary estimation of the background population of the parish during the study period was made by taking the

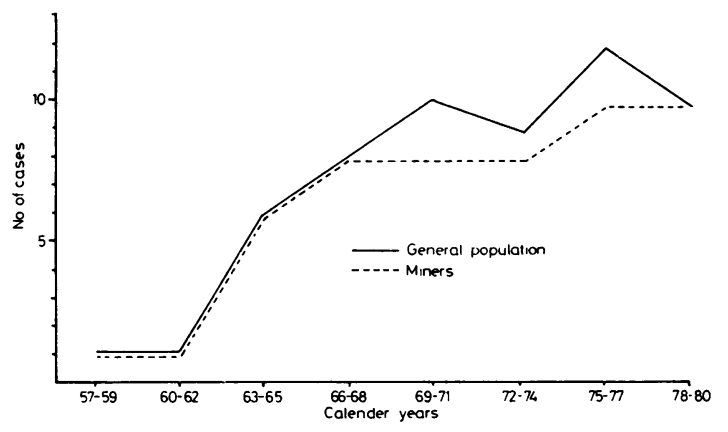

Number of cases of lung cancer during 1957-80 per three year period among miners and in the general population (miners included) in the parish of Grängesberg; the population aged over 50 has been slightly decreasing. 
Table 1 Exposure to underground iron mining among cases and referents aged 50 and over as obtained from the death records in the parish of Grängesberg 1966-77

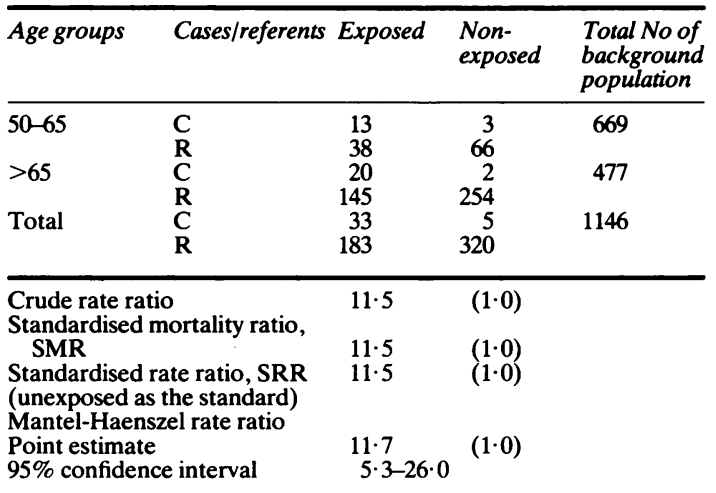

average of the censuses from 1965, 1970, and 1975. The censuises use the age strata corresponding to 50-64 and 65 and older.

\section{ASSESSMENT OF OCCUPATIONAL EXPOSURE AND} SMOKING

Lists of the subjects were submitted to the mining company for the identification of those who had been employed and for the detailed assessment of working time underground (first and last year). Information about smoking habits in the matched series of cases and referents of miners was obtained by telephone interviews with the next of kin of the deceased subjects. People who had never smoked or had stopped smoking more than 20 years before death were considered non-smokers.

The first measurements of the radon daughter levels in the mine were made in 1969-70 and showed levels in the range of 0.3 to 1.0 working level. The levels before 1969 can only be estimated, but according to the information available about changes in the ventilation system, it seems reasonable to suppose that the average exposure levels for the period 1920-69 was about 0.5 working level, somewhat lower before the introduction of the mechanical ventilation in 1955-6 and slightly higher thereafter until 1970, when the modern force ventilation system was introduced. With this new ventilation, the levels have been reduced to well below $0 \cdot 3$ working level.

\section{STATISTICAL METHODS}

The statistical analysis of the data were based on the Mantel-Haenszel procedure for the calculation of p-values (taking the form of the McNemar test for the matched series) and for the estimation of the overall rate ratio. ${ }^{9}$ The determinations of the standardised rate ratios and approximative (test-based) confidence intervals of the rate ratios follow the principles outlined by Miettinen. ${ }^{1011}$

\section{Results}

There were 38 cases and 503 referents available for 1967-77 (table 1). The crude rate ratio for lung cancer among the underground workers compared with nonexposed individuals in the parish was $11 \cdot 5$. Since the standardised mortality ratio (SMR) was also 11.5 , there was no indication of confounding from age (a further analysis using four age strata showed no confounding from age). With regard to the analysis of the influence of smoking, there were some losses of subjects due to the difficulties in assessing exposure time or smoking habits and finally only 28 pairs (case and referent) remained for the analysis. Ten pairs were discordant for smoking; in six pairs the case was a smoker and in the remaining four the referent was a smoker. The rate ratio for lung cancer among smoking miners as against non-smoking miners was consequently 1.5 (table 2 ). The exposure time underground for smokers was 29 years and for nonsmokers 29.4 years. Smoking referents had an average exposure of 26.9 years and the non-smoking referents were exposed for 25.7 years. Dissolving the pairs did not change the risk ratio of $1 \cdot 5$, indicating no particular confounding from the matching factors. Allowing for the differences in exposure time between smokers and non-smokers by stratification on duration of underground work $(<28 ; \geqslant 28$ years, dichotomising at the average) still resulted in an SMR of $1 \cdot 5$.

Based on the census information about the population of the parish and the proportion of exposed and non-exposed referents (table 1), the average size of the exposed population during the study period was estimated as 417 individuals (according to the mining company about 420 were occupied in underground work during the period). Thus in the calculations an average of 417 were considered to constitute the exposed group during the study period of 12 years (1966-77) with 244 aged

Table 2 Smoking habits among the 28 matched pairs of underground miners

\begin{tabular}{|c|c|c|}
\hline \multirow[t]{2}{*}{ Cases } & \multicolumn{2}{|l|}{ Referents } \\
\hline & Smokers & Non-smokers \\
\hline Smokers & 17 & 6 \\
\hline $\begin{array}{l}\text { Non-smokers } \\
\text { Risk ratio }\end{array}$ & \multirow{2}{*}{\multicolumn{2}{|c|}{$\begin{array}{l}1.5 \\
0.4-5 \cdot 3\end{array}$}} \\
\hline $95 \%$ confidence interval & & \\
\hline
\end{tabular}

The discordant pairs, here obtained as 6 to 4 , were 2 to 1 in ages $50-65$ and 4 to 3 in ages above 65 . 
50-65 providing 2928 person-years of observation. With 13 cases having occurred, the mortality rate was 44.4 cases per $10^{4}$ person-years in the age range 50 to 65 . Similarly, for ages above 65 the annual average population amounted to 173 individuals with 20 cases occurring in 2076 person-years of observation, a rate of 96.3 per $10^{4}$ person-years. The unexposed annual average population in the parish was estimated as 425 men aged $50-65$ and with three cases in this age group the mortality rate was 5.9 cases per $10^{4}$ person-years. For ages of over 65 , two cases in an annual average population of 304 individuals provided a rate of $5 \cdot 5$ cases per $10^{4}$ person-years.

Assuming an exposure level of 0.5 working level during 11 months a year (11 months might be taken as a reasonable, effective exposure time for these miners when disregarding holidays) and an average exposure time (smokers and non-smokers) of 27 years for the 13 cases aged $50-65$ and $30 \cdot 4$ years for the 20 cases over 65, the cumulative exposure was calculated to be 148.5 and 167.2 WLM, respectively (exposure from radon daughters in dwellings is disregarded as amounting to only a few working level months). With an excess rate of 44.4 minus 5.9 (or 38.5 ), and 96.3 minus 5.5 (or 90.8 ) cases per $10^{4}$ person-years, respectively, the calculated risk estimates for this mining population are 25.9 and 54.3 cases per $10^{\circ}$ person-years and WLM, considering the ages 50-65 and over 65 , respectively (table 3 ). With a requirement of 10 years of underground exposure time and 15 years' allowance for induction latency time the excess risk (and the number of cases) is somewhat reduced, especially in those aged 65 and older.

Because of the uncertainty in the estimation of the exposure level, some alternative calculations should be considered, based on the measurements from 1969-70 which showed a range from 0.3 to $1 \cdot 0$ working level. The derivable risk estimates would then be from 13.0 to 43.2 and from 27.2 to 90.5 cases per $10^{6}$ person-years and WLM in the two age groups, respectively. Taking the random variation into account an even broader range might be discussed, however.

Table 3 Age specific estimates of excess risk of lung cancer due to radon

\begin{tabular}{|c|c|c|c|}
\hline \multirow[t]{2}{*}{$\begin{array}{l}\text { Age at death } \\
\text { of cancer }\end{array}$} & \multicolumn{3}{|c|}{$\begin{array}{l}\text { Excess risk, cases per } 10^{\circ} \text { person-years, and working } \\
\text { level month }\end{array}$} \\
\hline & BEIR III & Grängesberg & $\begin{array}{l}\text { Grängesberg } \\
\text { l0a exp time } \\
\text { l5a induction- } \\
\text { latency time }\end{array}$ \\
\hline $\begin{array}{l}50-65 \\
>65\end{array}$ & $\begin{array}{l}20 \\
50\end{array}$ & $\begin{array}{l}26 \\
54\end{array}$ & $\begin{array}{l}22 \\
45\end{array}$ \\
\hline
\end{tabular}

\section{Discussion}

The results of this study confirm earlier findings of a considerable risk of Swedish (non-uranium) miners developing lung cancer compared with non-miners. Even non-smoking miners seem to be at a rather high risk.

Considering the various validity aspects of this study, the acquisition of cases and referents from the parish register could be thought of as not being entirely satisfactory due to incompleteness of such registers. The registers of deaths and burials in Sweden, however, contain fairly complete information about the diagnoses as transferred from the death certificates; this has been experienced in the present investigation as well as in other studies.

Some migration apparently takes place in and out of a parish but the case-referent approach is preferably applicable to dynamic populations," and no distortion of the material in this respect would be expected, unless a differential migration has occurred with regard both to exposure and cause of death, a phenomenon that is unlikely. With regard to the matched series, it should be emphasised that only referents having died of a non-malignant disease were selected. The reason is that the exposure (smoking) might cause not only the disease under study (lung cancer) but also other cancers ${ }^{12}$ and the inclusion of these would tend spuriously to increase the frequency of smoking among the referents compared with the source population for the cases. Therefore, the inclusion of other types of cancers, some of them being related to smoking, would have given an even lower rate ratio for lung cancer than the one obtained for smoking miners as against non-smoking miners. Still, the well-known relationship of smoking and cardiovascular disease ${ }^{12}$ would be expected to give a somewhat high frequency of exposure among the referents and consequently a conservative risk estimate.

The observation from some other mines that even non-smoking miners have about the same risk as the smokers of developing lung cancer has been discussed elsewhere from a pathogenic point of view. ${ }^{31314}$ Thus various physiological or pathological processes in the mucous membranes of the respiratory tract might affect miners and change some of the dimensions that are critical with regard to the possibility of the alpha radiation reaching sensitive structures in the bronchial epithelium. An increase of the thickness of the mucous lining, say, due to dust or to irritants in the mine atmosphere, may protect against the short ranging alpha radiation. A breakdown of the cylinder epithelium, on the other hand, might tend to decrease distances and enhance the effectiveness of the radiation. 
The validity of information about smoking habits as obtained through interviews with next of kin may be criticised with regard to a "memory bias."

Generally speaking, however, this critical point of assessing exposure through interviews has been recently studied in the context of occupational health epidemiology, and an acceptable agreement between interviews and other sources with regard to the occupational exposure ${ }^{15}$ and smoking histories ${ }^{16}$ has been found. In principle, a random misclassification of smoking would tend to level out the risk of lung cancer between smokers and non-smokers, but hardly to the extent seen in this study. The slightly longer exposure time for smokers could mean some confounding in this particular context and might marginally contribute to the increased rate ratio for the smokers compared with the non-smokers. Since dissolving of the pairs did not change the ratio of $1 \cdot 5$, the matching factors seem to imply little or no confounding, however, and since the stratification on duration of underground work ( $<28$ and $\geqslant 28$ years) gave an SMR of 1.5 , the interpretation would be that in this context there is no pertinent confounding from exposure time to underground mining.

The rather high risk of lung cancer among the miners as compared with non-miners is partly explained by the fact that the local population becomes the reference in this case-referent approach, and Grängesberg is a small town with a low background of lung cancer mortality. A comparison of the lung cancer mortality in Grängesberg with the national average shows that the lung cancer mortality among the exposed miners is "only" about six times that of the national average (table 4).

Epidemiological studies of several groups of miners with exposure to radon daughters have shown an excessive incidence of lung cancer. The available quantitative information has been summarised in the BEIR III report.' ${ }^{2}$ The various estimates of risk for lung cancer among the groups of underground miners have ranged from six to 47 excess cases per $10^{\circ}$ person-years and WLM. This variation probably reflects in large part the differences in age and follow

Table 4 A comparison of unexposed and exposed lung cancer death rates per $10^{4}$ person-years in Grängesberg (1966-77) with the Swedish national average in 1972 among men aged 50 and over

\begin{tabular}{llll}
\hline Age at death & \multicolumn{2}{l}{ Grängesberg } & National average \\
\cline { 2 - 3 } & Exposed & Non-exposed & \\
\hline $50-65$ & $44 \cdot 4$ & 5.9 & $5 \cdot 5$ \\
$>65$ & 96.3 & 5.5 & $20 \cdot 4$ \\
Total & 65.9 & 5.7 & $11 \cdot 5$ \\
\hline
\end{tabular}

up time of the various populations. The lowest risk estimate derives from the United States uranium miners, whereas the highest comes from a subgroup of Czechoslovakian uranium miners, who began underground work at the age of $\mathbf{4 0}$ or later. As an average for active miners, the BEIR III uses 18 excess cases per $10^{6}$ person-years and WLM, without any specified age-standard.

Table 3 shows the BEIR III estimates of age specific lung cancer excess due to radon daughter exposure in number of cases per $10^{6}$ person-years and WLM, together with the estimates obtained from this study. The BEIR III estimates were based on what was considered to be the best available data from Canadian and Czechoslovakian miners and on the assumption that the smoking habits of the exposed population is typical of the whole population of which it is a segment. If these age specific risk estimates are used to calculate an "expected excess number" of cases in a population with the age distribution (above 50 ) of the exposed Grängesberg miners, one gets $32 \cdot 3$ cases per $10^{6}$ person-years and WLM from the BEIR III estimates, a figure which is in reasonably close agreement with the $37 \cdot 6$ obtained in this study, as based on the estimate of 0.5 working level as an average exposure level. It might be noted that the calculations of the excess risks in each age stratum in the Grängesberg study gave slightly higher estimates than in BEIR III (table 3).

It is also perhaps important to emphasise somewhat the need for using adequately age standardised risk estimates when comparing different mining groups. This is also underscored by a comparison with another study on Swedish zinc-lead miners. ${ }^{13}$ The crude risk estimate for those miners was 30.4 excess lung cancer deaths per $10^{6}$ person years and WLM in ages over $50 .^{2}$ This estimate has been regarded as high, ${ }^{2}$ but applying the age specific risk estimates from the BIER III to that particular group of miners one can estimate an "expected" risk of 30.2 excess lung cancer deaths per $10^{6}$ person-years and WLM, which is about the same "expected" estimate as for the Grängesberg miners.

The effect of smoking on the risk estimates has not yet been fully evaluated in publications since, except for the zinc-miners, ${ }^{13}$ the estimates are derived from mixed populations of smokers and non-smokers. If the smoking and radiation risks are additive the excess estimate in table 3 would apply to both smokers and non-smokers. Judging from some of the presumably most "mature" mining populations that have been specifically studied in this respect, ${ }^{1317}$ an additive interrelationship seems the more likely. There is also some justification for the belief that cases could develop among non-smokers at later ages $^{1318}$ than has been fully accounted for in many 
studies in this field since the follow-up periods have been limited.

The crude incidence rates for non-smoking miners may be calculated, assuming the overall mortality rate of lung cancer to be the sum of the rates for smokers and non-smokers-that is, $\mathrm{A}=\mathrm{aF}+\mathrm{aRR}$ (1-F), where $A$ is the overall rate, a the rate for non-smokers, $F$ the fraction of non-smokers in the population and RR the rate ratio, smokers $v$ nonsmokers. ${ }^{19}$ From tables 1 and 2 it is possible to obtain the rate among the non-smoking miners of Grängesberg; $A=33 /(417 \times 12) \times 10^{4}=65.9$ (table 1); $F=7 / 28=0.25$ (table 2); RR $=1.5$ (table 2) alternatively SMR $=1.5$ and hence $a=48.0$. Assuming the cumulative exposure for the nonsmokers to be that of the non-smoking cases of table 2 - $161 \cdot 7$ WLM - gives a lung cancer risk of $29 \cdot 7$ cases per $10^{6}$ person-years and WLM among non-smokers. This estimate is reasonably close to the one of 34.8 , calculated for the non-smoking zinc lead miners, ${ }^{19}$ although the small numbers behind create great uncertainties. Similarly from smoking cases of table 2, with a cumulative exposure of $159.5 \mathrm{WLM}$, the risk was formally calculated to $45 \cdot 1$ cases per $10^{6}$ personyears and WLM.

Taken together, these estimates both for smokers and non-smokers seem to suggest a slightly conservative estimate of roughly $30-40$ cases per $10^{6}$ person-years and WLM to be applied on a life time basis both for smoking and non-smoking miners aged over 50 .

We are indebted to Mr Olle Söderkvist for compiling the data on radon measurements and introducing us to the history of mining in Grängesberg. We also thank Dr Lennart Sundell for fruitful discussions and Ms Anna-Lena Björklinger for typing the manuscript. This work was supported by the Swedish Work Environment Fund grant 78/113.

\section{References}

' Harley JH. Radioactive emissions and radon. Bull NY Acad Med 1981:57:883-96.

${ }^{2}$ National Academy of Sciences, Committee on the Biological Effects of Ionizing Radiation (BEIR 1980). The effects on populations of exposures to low levels of ionizing radiation. Washington, DC: NAS, 1980. (Typescript edition.)

${ }^{3}$ Altshuler B, Nelson N, Kuschner M. Estimation of lung tissue dose from the inhalation of radon and daughters. Health Phys 1964;10:1137-61.

4 Statens planverk rapport 54. Stralning $i$ byggnader (Radiation in buildings.) Stockholm: Statens planverk, 1981.

s Swedish Energy Commission. Energy: health, environmental and security hazards. Stockholm: SEG, 1978:253. (In Swedish with an English summary.)

- Cohen BL. Health effects of radon from insulation of buildings. Health Phys 1980;39:937-41.

${ }^{7}$ Harley NH, Pasternack BS. A model for predicting lung cancer risks induced by environmental levels of radon daughters. Health Phys 1981;40:307-16.

${ }^{8}$ Edling $C$. Lung cancer and smoking in a group of iron ore miners. Am J Ind Med 1982;3:191-9.

- Mantel N, Haenszel W. Statistical aspects of the analysis of the data from retrospective studies of disease. $J$ Natl Cancer Inst 1959;32:719-48.

${ }^{10}$ Miettinen OS. Standardization of risk ratio. Am J Epidemiol 1972;96:168-72.

"Miettinen OS. Estimability and estimation in case-referent studies. Am J Epidemiol 1976;103:226-35.

${ }^{12}$ United States Department of Health, Education and Welfare. Smoking and health: a report of the Surgeon General. Washington: USDHEW, 1979.

${ }^{13}$ Axelson O, Sundell L. Mining, lung cancer and smoking. Scand J Work Environ Health 1978;4:46-52.

${ }^{14}$ Axelson O, Sundell L. Mining, lung cancer and smoking. Scand J Work Environ Health 1980;6:227-31.

${ }^{15}$ Hardell L. Relation of soft-tissue sarcoma, malignant lymphoma and colon cancer to phenoxy acids, chlorophenols and other agents. Scand J Work Environ Health 1981;7:119-30.

${ }^{16}$ Pershagen G, Axelson O. A validation of questionnaire information on occupational exposure and smoking. Scand $J$ Work Environ Health 1982;8:24-8.

"Dahlgren E. Lung cancer, cardiovascular disease and smoking in a group of miners. Läkartidningen 1979;76:4811-4.

${ }^{18}$ Archer VE, Wagoner JK, Lundin FE. Uranium mining and cigarette smoking effects on man. JOM 1973;15:204-11.

${ }^{19}$ Axelson O, Edling C. Health hazards from radon daughters in dwellings in Sweden. In: Rom WN, Archer VE, eds. Health implications of new energy technologies. Ann Arbor: Ann Arbor Science Publishers Inc, 1980:79-87. 